\title{
Identification of phenolic acids of Pandan anggur (Sararanga sinuosa Hemsley) fruits and their potential antiglycation through molecular docking study
}

\author{
Vita Purnamasari ${ }^{1,4, *}$, Teti Estiasih ${ }^{2}$, Hidayat Sujuti ${ }^{3}$, Simon Bambang Widjanarko \\ ${ }^{1}$ Doctoral Program of Agroindustrial Technology, Faculty of Agricultural Technology, Brawijaya University, Malang, Indonesia. \\ ${ }^{2}$ Department of Agricultural Product Technology, Faculty of Agricultural Technology, Brawijaya University, Malang, Indonesia. \\ ${ }^{3}$ Department of Biochemistry, Faculty of Medicine, Brawijaya University, Malang, Indonesia. \\ ${ }^{4}$ Department of Biology, Faculty of Mathematics and Natural Science, Cenderawasih University, Jayapura, Indonesia.
}

\begin{tabular}{l}
\hline ARTICLE INFO \\
\hline Received on: $29 / 08 / 2020$ \\
Accepted on: $26 / 11 / 2020$ \\
Available online: $05 / 02 / 2021$ \\
\\
\hline Key words: \\
Antiglycation, Sararanga \\
sinuosa, Molecular docking, \\
Pandan anggur, Phenolic \\
acids.
\end{tabular}

\begin{abstract}
Berries are known to contain polyphenols, including phenolic acids, and known Sararanga sinuosa fruits are classified as berries. Identification of phenolic acids of the $S$. sinuosa fruit extract was done by liquid chromatography coupled to high-resolution mass spectrometry (LC-ESI-Orbitrap-MS). The prediction of the interaction and potency of antiglycation of phenolic acids with the protein surface of human serum albumin (HSA) was carried out by molecular docking. The phenolic acids in the S. sinuosa fruit extracts were syringic acid, isovanillic acid (hydroxybenzoic acid group), chlorogenic acid, 2-hydroxycinnamic acid, sinapinic acid, caffeic acid, and ferulic acid (hydroxycinnamic acid group). Chlorogenic acid, caffeic acid, syringic acid, 2-hydroxycinnamic acid, and sinapinic acid bind to HSA at the FA7 site (subdomain IIA), whereas isovanillic acid and ferulic acid bind to FA6 (between subdomains IIA and IIB) and FA1 sites (subdomain IA), respectively. Phenolic acids that bind to the amino acid residues of Lys195 and/or Lys199, namely chlorogenic acid, caffeic acid, syringic acid, 2-hydroxycinnamic acid, and sinapinic acid, are predicted to occupy the sites for the glycation reaction in HSA. In conclusion, the $S$. sinuosa fruit extract contains seven phenolic acids that can bind to HSA. Five of them, namely chlorogenic acid, caffeic acid, syringic acid, 2-hydroxycinnamic acid, and sinapinic acid, have potential to play a role in antiglycation.
\end{abstract}

\section{INTRODUCTION}

The genus Sararanga is a member of the Pandanaceae family. It is known that the Sararanga genus consists of Sararanga philippinensis which is found in the Philippines and S. sinuosa Hemsley which spreads in Papua, Papua New Guinea, and the surrounding islands (the Solomon Islands and Fauro Island). Sararanga sinuosa fruit is classified to as berries that are kidneyshaped, and are green when young and red when old (Keim, 2009; Stone et al., 1998). The tribes of Tepra in Depapre, Jayapura Regency,

\section{*Corresponding Author}

Vita Purnamasari, Department of Biology, Faculty of Mathematics and Natural Science, Cenderawasih University, Jalan Kampwolker Perumnas III, Yabansai, Heram, Jayapura, Indonesia.

E-mail: purnamasari.vita@yahoo.co.id and the Yapen people consume $S$. sinuosa fruit as a fresh fruit (Purwanto and Munawaroh, 2010). Sararanga sinuosa fruit is also potentially used in fruit preparations, such as juice and jam, based on its characteristics as a berry (Purnamasari et al., 2018, 2019).

Berries are generally known to be rich in phenolic compounds, one of which is the phenolic acid (Nile and Park, 2014) as in rowanberry, chokeberry, blueberry, sweet rowanberry, Saskatoon berry (Mattila et al., 2006), blackberries (Cosmulescu etal.,2017), Caucasianblueberries, and bilberries(Colaketal.,2016). Phenolic acids in berries include p-coumaric, caffeic acid, ferulic acid sinapinic acid, cinnamic acid, gallic acid, syringic acid, vanillic acid, protocatechuic acid, p-hydroxybenzoic acid (Mattila et al., 2006), chlorogenic acid, and neochlorogenic acid (León-González et al., 2013). Phenolic acid is found as a secondary metabolite of plants and has biological activities, such as anti-diabetes (Zengin et al., 2018), antioxidants (Li et al., 2011), antimicrobials (Stojković et al., 2013), and anti-inflammatory (Hwang et al., 2014). 
Albumin in diabetes mellitus can have glycation due to hyperglycemia (Anguizola et al., 2013). The glycation process is then followed by condensation and oxidative modification to produce a product known as the advanced glycation end product (AGE). The emergence of excessive AGE can have implications for several pathological conditions; and one of them is diabetes complications such as cataracts, atherosclerosis, nephropathy, vasculopathy, proliferative retinopathy, and aging (Ulrich and Cerami, 2001). Phenolic acids, such as isoferulic acid, are known to occupy the position of amino acids that play a role in the glycation process in HSA (Arfin et al., 2018). It is known that one type of mechanism for the inhibition of AGE formation is to change free amino groups of proteins and peptides to prevent sugar sticking (Abbas et al., 2015; Cervantes-Laurean et al., 2006). The purpose of this study is to identify the type of phenolic acid of the $S$. sinuosa fruit extract, prediction of the interaction, and potency of antiglycation of phenolic acid of the $S$. sinuosa fruit extract on the HSA protein surface by molecular docking. It is known that glycated HSA is used as a biological marker to monitor the glycemic status of diabetic patients (Roohk and Zaidi, 2008; Shimizu et al., 2019).

\section{MATERIAL AND METHODS}

\section{Fruit samples}

Samples of the $S$. sinuosa fruit, red color (ripe), were collected from around the Bumi Perkemahan Pramuka, Waena, Jayapura, Papua, Indonesia, in July 2018. The samples were then placed in a styrofoam box that has been filled with dry ice to maintain its freshness and then brought on the same day to Malang. The sample was then stored in a freezer $\left(-4^{\circ} \mathrm{C}\right)$ for further analysis.

The authentication of $S$. sinuosa fruit samples was carried out at the Herbarium Bogoriense, Botany Division, Research Center of Biology-Lembaga Ilmu Pengetahuan Indonesia (LIPI), Bogor, Indonesia. The results of the sample authentication showed that it is true that the sample is $S$. sinuosa Hemsley fruit as evidenced by the identification letter-number 1056/IPH.1.01/If.07/X/2020.

\section{Extraction of Pandan anggur (S. sinuosa) fruits}

Frozen $S$. sinuosa fruits, red color (ripe) (3 gs), were homogenized with a mortar and pestle mixed with $60 \mathrm{ml}$ of distilled water. The mixture was then extracted with a sonicator for 30 minutes after which it was centrifuged at 5,000 rpm for 10 minutes and the supernatant was separated. The extraction process was repeated three times. All supernatants were collected and stored at $-4^{\circ} \mathrm{C}$ for the next day they were analyzed using LC-ESIOrbitrap-MS.

\section{LC-ESI-Orbitrap-MS analysis}

Investigation of phenolic acid of $S$. sinuosa water extract was carried out by UHPLC-HRMS. UHPLC analysis was carried out with the Dionex Ultimate 3000 RSLC system (Thermo Fisher Scientific, Bremen, Germany) consisting of the autosampler equipment with column ovens, column compartment trays, and binary pumps with a built-in solvent degassed, all directed with XcaliburTM software. Separation chromatography was carried out using Hypersil Gold aQ $(50 \times 1 \mathrm{~mm}, 1.9 \mu \mathrm{m}$ particle size,
Thermo Fisher Scientific). 5- $\mu 1$ sample volume was injected with full loop injection mode and the column oven was set at $30^{\circ} \mathrm{C}$. Separation was carried out at a constant speed of $40 \mu \mathrm{l} /$ minutes by using mobile phase A ( $0.1 \%$ formic acid in water) and B $(0.1 \%$ formic acid in acetonitrile) following a gradient of 0-40 minutes: 4\%-20\% B; 40-60 minutes: 20\%-35\% B; 61-95 minutes: $98 \% \mathrm{~B}$; and 65-70 minutes: 5\% B (Sun et al., 2013).

The chromatography system was connected to the Q Exative $^{\mathrm{TM}}$ hybrid quadrupole-Orbitrap ${ }^{\mathrm{TM}}$ mass spectrometer (Thermo Fisher Scientific, Bremen, Germany). The instrument was operated using a heated electrospray interface (HESI II) (Thermo Fisher Scientific, Bremen, Germany) in the positive ionization mode. The ESI source parameters are as follows: capillary temperature of $350^{\circ} \mathrm{C}$; sheath gas 55 arbitrary unit (au); auxiliary gas $15 \mathrm{au}$; sweep gas $3 \mathrm{au}$; spray voltage 2,500 V; auxiliary gas heater temperature $300^{\circ} \mathrm{C}$; and S-lens radio frequency level 50 .

All screening data were obtained using a full scan/ddMS2 mode. MS data were obtained with full range acquisition covering $m / z$ 50-750 with a resolution [full width at half maximum (FWHM) at 15 seconds] of 70,000. The automatic gain control (AGC) was set to $3 \times 106$ with a maximum injection time of 250 $\mathrm{ms} . \mathrm{MS} / \mathrm{MS}$ fragmentation was carried out in dd-MS2 mode with a resolution (FWHM at 15 seconds) of 17,500. The target AGC value was set at $1 \times 105$ with a maximum injection time of $50 \mathrm{~ms}$. Dynamic exclusion was set to 6 seconds. All traces of the extracted mass were based on a $2.0 \mathrm{~m} / \mathrm{z}$ mass isolation window. Fragmentation was achieved in higher-energy collisional dissociation (HCD) cells in normalized collision energy 15, 35, and 50 .

The final spectrum acquisition analysis and element composition calculations were carried out with Compound Discoverer 3.3 (Thermo Fisher Scientific, Bremen, Germany), a metabolomic data analysis software. The tentative identification of phenolic acid structures iswas based on the accurate mass ( $\pm 5 \mathrm{ppm})$ with mzCloudTM (https://www.mzCloud.org) MS/MS Library.

\section{Preparation of ligand and protein target for molecular docking}

The results of the identification of phenolic acids of $S$. sinuosa fruit water extracts (Table 1) were used as ligands for analysis of complex formation with HSA. The three-dimensional structure of phenolic acid extracts of $S$. sinuosa fruit water consists of isovanillic acid, 2-hydroxycinnamic acid, chlorogenic acid, caffeic acid, syringic acid, sinapinic acid, and ferulic acid obtained from the PubChem compound database (https//:www.pubchem. ncbi.nlm.nih.gov) in the SDF chemical-data file format. Human serum albumin (HSA) was used for targeting. The structure of phenolic acids of $S$. sinuosa fruit extract acids was minimized with Open Babel which was integrated with PyRx 0.8 (Dallakyan and Olson, 2015) with energy minimization parameter: mmff94 force field and steepest descent optimization algorithm (O'Boyle et al., 2011), while the three-dimensional structure of the HSA is free with ID 1 AO6 as a receptor; it was obtained from the bank database (http//:www.rcsb.org/pdb/home/home.do). Modification of HSA (eliminating myristate and water molecules) was carried out using PyRx (Dallakyan and Olson, 2015).

\section{Molecular docking}

The interaction between HSA and phenolic acid of the $S$. sinuosa fruit extract was analyzed using AutoDock Vina 
which is integrated into the PyRx 0.8 (http://pyrx.sourceforge. net) (Dallakyan and Olson, 2015; Trott and Olson, 2009). The docking method was carried out to evaluate the binding affinities and to explain the antiglycation potential of the phenolic acid fruit extracts of $S$. sinuosa. Docking was carried out by setting HSA as a rigid molecule and phenolic acid as a flexible molecule with blind docking using the maximum grid box (X: 74.0825, Y: 61.5488, and Z: 81.1510).

\section{Visualization and analysis of docking results}

The results of the docking and HSA binding interactions and phenolic acid binding were visualized with easy computeraided drug design (ezCADD) (http://dxulab.org/software). ezCADD is a web-based CADD modeling environment where one of its applications is to visualize $2 \mathrm{D} / 3 \mathrm{D}$ protein-ligand interactions (Tao et al., 2018). The analysis of the pattern of hydrogen bond interactions and hydrophobic contact between phenolic acid and HSA was carried out using LigPlot ${ }^{+}$(Wallace et al., 1995). The docking position of each HSA-phenolic acid complex was compared with the 3D HSA structure that binds ligands at the FA site (Ascenzi et al., 2015; Rabbani and Ahn, 2019) to predict the interaction. The antiglycation potential was predicted by the interaction of each phenolic acid with amino acid residues that play a role in the HSA glycation process (Barnaby et al., 2011; Lapolla et al., 2004).

\section{RESULTS AND DISCUSSION}

\section{LC-ESI-Orbitrap-MS qualitative analysis}

The results obtained from the identification of phenolic acid extracts of the $S$. sinuosa fruit with LC-ESI-Orbitrap-MS are shown in Table 1 and Figures 1 and 2. LC-ESI-Orbitrap-MS analyzed the extract of the $S$. sinuosa fruit in the positive ionization mode. High-resolution MS (negative and positive ionization modes) was used to obtain information about the structural picture and conjugation form of phenolic compounds, including phenolic acids. The identification of phenolic compounds, including phenolic acids, arewas based on retention times, accurate mass measurements, MS/MS data, and exploratory spectral data of specific metabolites in public repositories (mass bank) and was compared with data obtained in the literature (La Barbera et al., 2017).
Seven types of phenolic acids were identified from extracts of the $S$. sinuosa fruits, which were dominated by the hydroxycinnamic acid group (Table 1). This result is in line with the statement of Manach et al. (2004), where hydroxycinnamic acid derivatives are a group of phenolic acids that are commonly found in many natural sources. The five compounds identified as the hydroxycinnamic acid group were 2-hydroxycinnamic acid, chlorogenic acid, caffeic acid, sinapinic acid, and ferulic acid. The two compounds identified as the hydroxybenzoic acid group were syringic acid and isovanillic acid, respectively. The identification of all phenolic acids of water extracts was done by mzCloudTM (https://www.mzCloud.org) MS/MS Library. Some berries, such as blueberries (Su et al., 2017), Don berries [Corema album (L..)] (León-González et al., 2013), Vaccinium arctostaphylos L., and Vaccinium myrtillus L. (Colak et al., 2016), are known to contain phenolic acids.

\section{Prediction of the interaction of phenolic acids of $S$. sinuosa fruit extract with HSA protein surface}

Molecular docking studies were carried out to predict the affinity bonds of phenolic acids of the $S$. sinuosa fruits on the HSA protein surface and analyze their binding methods. Molecular docking is a virtual environment to support complex details of ligand-protein interactions. Docking results of phenolic acid of $S$. sinuosa fruit extract on HSA showed that all phenolic acids could bind to HSA (Figure 4). Chlorogenic acid showed the highest binding affinity, $-8.1 \mathrm{kcal} / \mathrm{mol}$, among other phenolic acids in the fruit extract of $S$. sinuosa. The affinity of the binding of phenolic acid to the fruit extract of $S$. sinuosa is as follows: chlorogenic acid $>2$-hydroxycinnamic acid $>$ sinapinic acid $>$ syringic acid $=$ caffeic acid $>$ isovanillic acid $>$ ferulic acid (Table 2). It might suggest that the binding of chlorogenic acid to HSA is easier, as indicated by the lower binding affinity compared to the other phenolic acids. The amount of free energy binding is an indicator of the ability of bioactive compounds to bind to target proteins. In any spontaneous process, proteinligand bonds only occur when changes in the system free energy $(\Delta \mathrm{G})$ are negative when the system reaches a constant equilibrium of pressure and temperature. Because the extension of the protein-ligand association is defined by the magnitude of the negative Gibbs free energy $(\Delta \mathrm{G})$, it can be assumed that

Table 1. Identification results of phenolic acids on the extract of $S$. sinuosa fruits.

\begin{tabular}{|c|c|c|c|c|c|c|}
\hline $\begin{array}{l}\text { Relative Time } \\
\text { (minutes) }\end{array}$ & Tentative identification & $\begin{array}{c}\text { Elemental } \\
\text { composition }[\mathrm{M}-\mathrm{H}]^{+}\end{array}$ & $\begin{array}{l}\text { Measured } \\
\operatorname{mass}(m / z)\end{array}$ & $\begin{array}{l}\text { Theoritical } \\
\text { mass }(m / z)\end{array}$ & $\begin{array}{c}\text { Accuracy } \\
(\text { ppm })\end{array}$ & Other ion $(m / z)$ \\
\hline \multicolumn{7}{|c|}{ Hydroxybenzoic acid } \\
\hline 1.611 & Syringic acid & $\mathrm{C}_{9} \mathrm{H}_{10} \mathrm{O}_{5}^{+}$ & 199.05957 & 199.06010 & -2.66251 & $155.07002 ; 140.04659 ; 123.04406$ \\
\hline 4.737 & Isovanillic acid & $\mathrm{C}_{8} \mathrm{H}_{8} \mathrm{O}_{4}^{+}$ & 169.04936 & 169.04954 & -1.06478 & $151.03876 ; 125.05962 ; 111.04410 ; 93.03369$ \\
\hline 13.810 & Isovanillic acid & $\mathrm{C}_{8} \mathrm{H}_{8} \mathrm{O}_{4}^{+}$ & 169.04938 & 169.04954 & -0.94647 & $151.03871 ; 111.04411 ; 125.05965 ; 93.03366$ \\
\hline \multicolumn{7}{|c|}{ Hydroxycinnamic acid } \\
\hline 1.314 & 2-hydroxycinnamic acid & $\mathrm{C}_{9} \mathrm{H}_{8} \mathrm{O}_{3}^{+}$ & 165.05409 & 165.0546 & -3.21106 & $147.0435 ; 123.0440 ; 119.04909 ; 95.04931$ \\
\hline 2.809 & Caffeic acid & $\mathrm{C}_{9} \mathrm{H}_{8} \mathrm{O}_{4}^{+}$ & 181.04907 & 181.0495 & -3.34163 & $163.03876 ; 145.02823$ \\
\hline 3.114 & Sinapinic acid & $\mathrm{C}_{11} \mathrm{H}_{12} \mathrm{O}_{5}^{+}$ & 225.07501 & 225.07575 & -3.28778 & $207.06480 ; 175.03864 ; 147.04376 ; 119.04913 ; 91.05442$ \\
\hline 3.135 & Chlorogenic acid & $\mathrm{C}_{16} \mathrm{H}_{18} \mathrm{O}_{9}^{+}$ & 355.10129 & 355.10236 & -3.01040 & $163.03873 ; 145.02821 ; 135.04385$ \\
\hline 3.348 & Caffeic acid & $\mathrm{C}_{9} \mathrm{H}_{8} \mathrm{O}_{4}^{+}$ & 181.04893 & 181.049535 & -3.34163 & $163.03867 ; 145.02823 ; 135.04390$ \\
\hline 3.729 & Ferulic acid & $\mathrm{C}_{10} \mathrm{H}_{10} \mathrm{O}_{4}^{+}$ & 195.06473 & 195.06519 & -2.33255 & 177.05412 \\
\hline
\end{tabular}



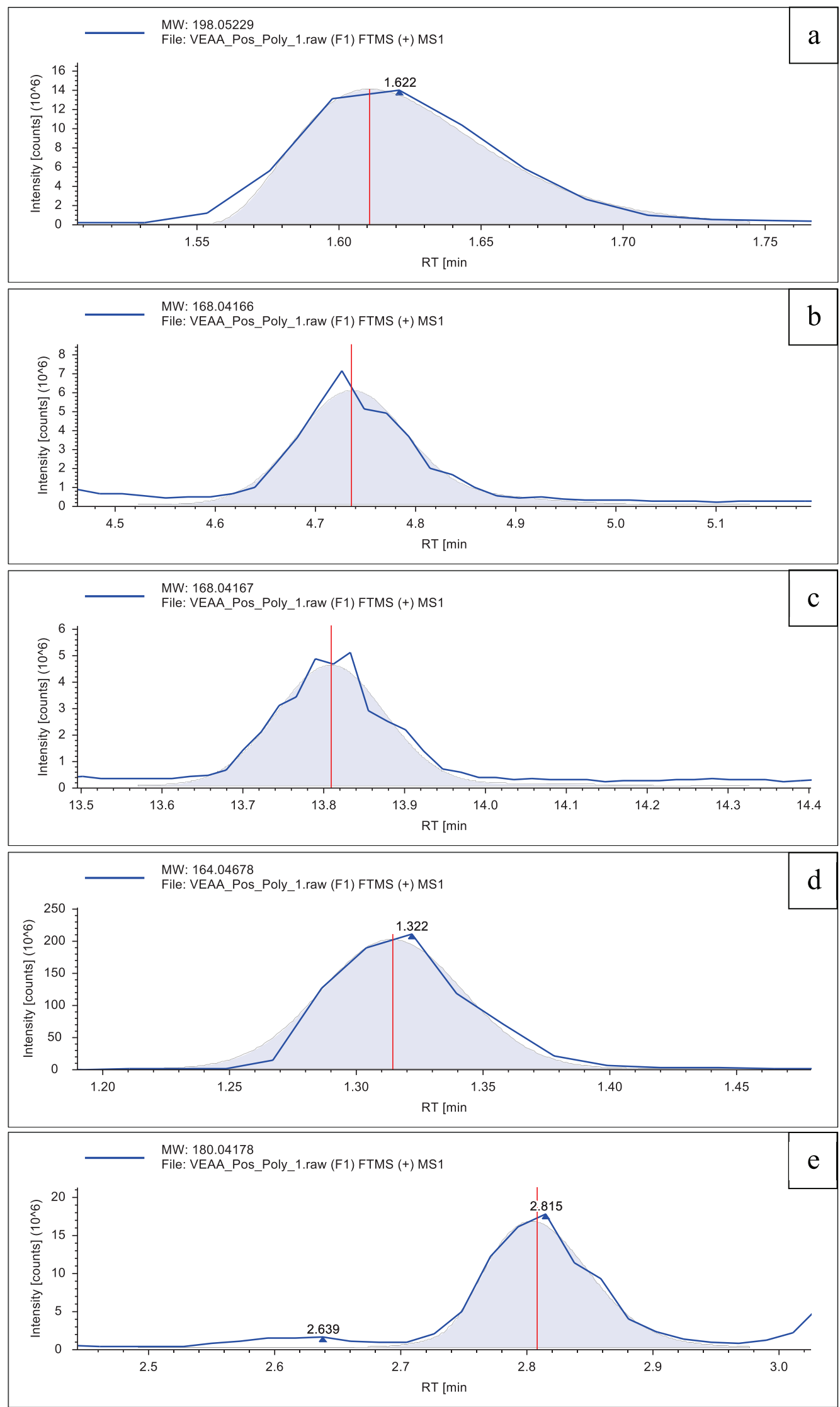

Figure 1. Single chromatogram of (a) syringic acid (b) isovanillic acid (c) isovanillic acid (d) 2-hidroxycinnamic acid (e) caffeic acid of water extract $S$. sinuosa fruits. 

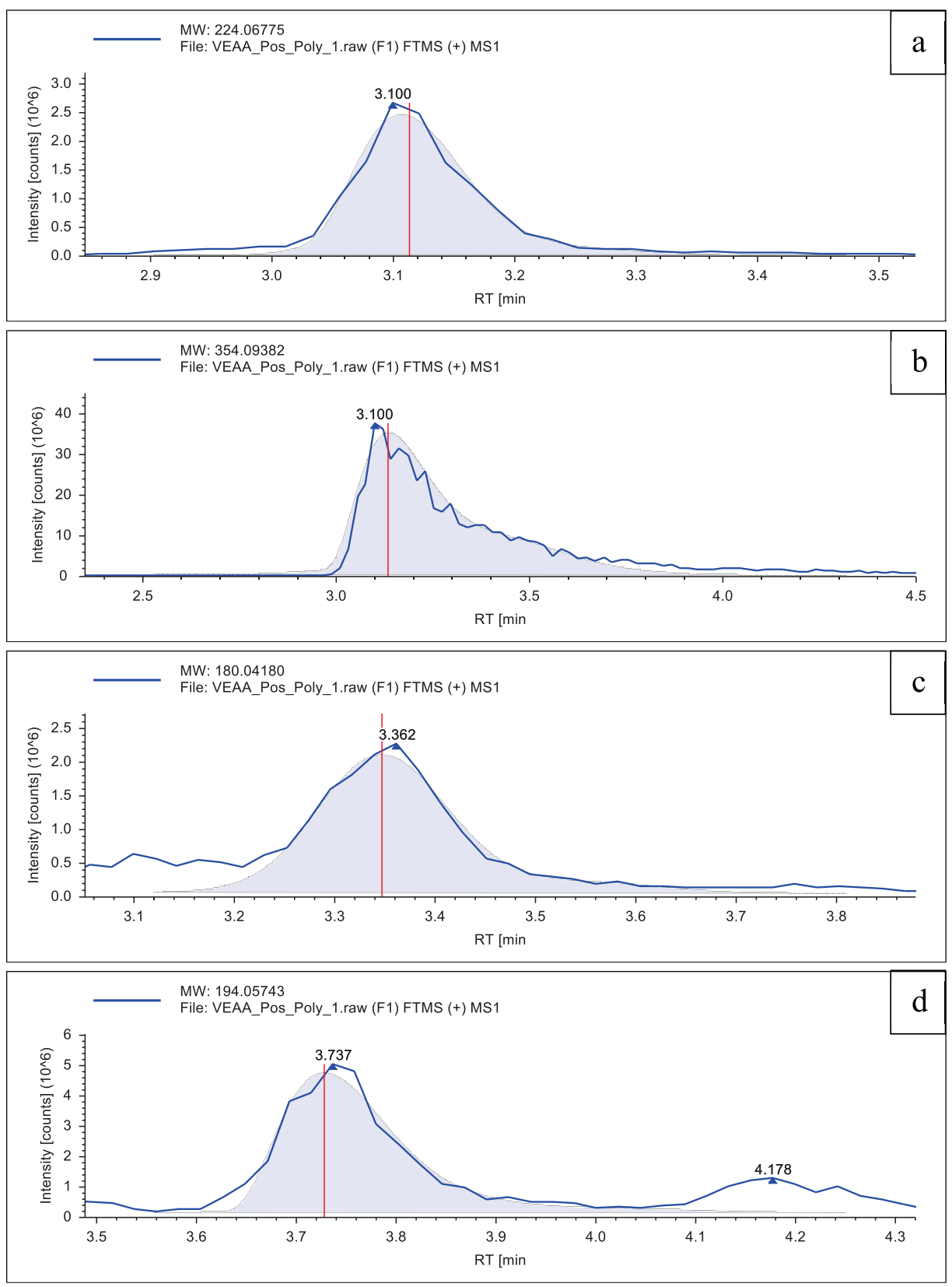

Figure 2. Single chromatogram of (a) Sinapinic acid (b) chlorogenic acid (c) caffeic acid and (d) ferulic acid of water extract $S$. sinuosa fruits.<smiles>[R]C(=O)c1c([R6])c([R6])c([R9])c([R6])c1[2H]</smiles><smiles>[R2]C(=O)/C=C/c1c([R8])c([R])c([R3])c([R])c1[R]</smiles>

A
Figure 3. Basic structure of phenolic acids: (A) hydroxybenzoic acids and (B) hydroxycinnamic acids.
Gibbs free energy $(\Delta \mathrm{G})$ determines the stability of any given protein-ligand complex or determines the bond that occurs between the ligand with the recipient (protein) (Gilson and Zhou, 2007).

The structure of phenolic acids influences their binding affinity to HSA. Phenolic acid is phenols (an aromatic ring bearing at least one hydroxyl substituent) which contain phenolic ring substances and at least one organic carboxylic acid function (Robbins, 2003) (Figure 3). An aromatic ring on a drug (ligand) often plays an essential role in its interaction with the target protein (Shafreen et al., 2017). In phenolic acids, their affinity with bovine serum albumin (BSA) is influenced by the molecular structure and the number of hydroxyl groups (He et al., 2010). 
Table 2. Binding affinity on HSA ( $\mathrm{kcal} / \mathrm{mol})$ and interaction residue phenolic acids on the extract of S. sinuosa fruits.

\begin{tabular}{|c|c|c|c|}
\hline Ligand & CID & $\begin{array}{c}\text { Binding affinity on HSA } \\
\text { (kcal/mol) }\end{array}$ & Interaction residue \\
\hline \multicolumn{4}{|c|}{ Hydroxybenzoic acid } \\
\hline \multirow[t]{2}{*}{ Syringic acid } & 10742 & -6.3 & HB: Tyr150, Arg222, Arg257(3), Ile290 \\
\hline & & & HI: Lys199, Leu219, Leu238, Ile264, Ser287, Ala291 \\
\hline \multirow[t]{2}{*}{ Isovanillic acid } & 12575 & -6.2 & HB: - \\
\hline & & & HI: Arg209, Ala213, Asp324, Leu327, Gly328, Leu331, Ala350, Lys351, Glu354 \\
\hline \multicolumn{4}{|c|}{ Hydroxycinnamic acid } \\
\hline \multirow[t]{2}{*}{ 2-Hydroxycinnamic acid } & 637540 & -6.6 & HB: Tyr150, Lys199, Arg222(2), Arg257(2), Ala291 \\
\hline & & & HI: Leu238, Leu260, Ile264, Ile290 \\
\hline \multirow[t]{2}{*}{ Sinapinic acid } & 637775 & -6.5 & HB: Ser192(2), Gln196, Arg222(2) \\
\hline & & & HI: Tyr150, Glu153, Lys195, Lys199, Leu238, Ala291 \\
\hline \multirow[t]{2}{*}{ Chlorogenic acid } & 1794427 & -8.1 & HB: Tyr150, Ser192, Gln196, Arg257(2), Ala291, Glu292 \\
\hline & & & HI: Glu153, Lys195, Lys199, Leu219, Phe223, Leu234, Leu238, His242, Leu260, Ile264 \\
\hline \multirow[t]{2}{*}{ Caffeic acid } & 689043 & -6.3 & HB: Ser192(2), Gln196, Arg222(2), Ala291 \\
\hline & & & HI: Tyr150, Glu153, Lys195, Lys199, Leu238, His242 \\
\hline \multirow[t]{2}{*}{ Ferulic acid } & 445858 & -6.0 & HI: Asp108(2) \\
\hline & & & HB: His146, Pro147, Lys190, Ala194, Asn429, Gln459 \\
\hline
\end{tabular}

$\mathrm{HB}=$ hidrogen bond; $\mathrm{HI}=$ hidrophobic interaction .

Ferulic acid interacts with HSA on amino acid residues Asp108, His146, Pro147, Lys190, Ala194, Asn429, and Gln459 (Table 2). It is known that the amino acid residues His146 and Lys190 are located at the FA1 site (green color in Figure 3). The FA1 site is located in subdomain IB (Ascenzi et al., 2015).

Chlorogenic acid, caffeic acid, syringic acid, 2-hydroxycinnamic acid, and sinapinic acid are docking at the FA7 cleft located in the subdomain IIA (green color in Figure 4), which interacts with HSA in the amino acid residues Tyr150 and Lys199. Besides, interactions also occur in the amino acid residue Arg222 in syringic acid, 2-hydroxycinnamic acid, sinapinic acid, and caffeic acid; amino acid residues Arg257 in syringic acid, 2-hydroxycinnamic acid, and chlorogenic acid; and amino acid residues Lys 195 in sinapinic acid, chlorogenic acid, and caffeic acid (Table 2). The FA7 cleft is also called Sudlow's site I which is the major drug-binding pocket. Sudlow's site I consists of amino acid residues Tyr150, Lys195, Lys199, Arg218, Arg222, Leu238, His242, Arg257, and Ala291 (Ascenzi et al., 2015; Rabbani and Ahn, 2019). Hydrogen bonds formed with polar amino acid residues Tyr150, Ser192, Gln196, Arg257(2), Ala291, and Glu292 in chlorogenic acid at HSA binding sites make a substantial contribution to the high binding affinity of the two compared to other phenolic acids (Wang et al., 2011).

Isovanillic acid was docked at HSA with nine amino acid residues. Four amino acid residues among them are interactions of amino acid residues that form the FA6 cleft (Ascenzi et al., 2015) located between the subdomains IIA and IIB (yellow color in Figure 4), namely Arg209, Asp324, Lys351, and Glu354 (Table 2).

\section{Prediction potency of antiglycation of $S$. sinuosa fruit phenolic acids on the surface HSA protein}

The prediction of the antiglycation ability of phenolic acids of $S$. sinuosa fruit extract on the surface of HSA protein was done by molecular docking. AutoDock Vina is used to analyze the interaction between phenolic acids of $S$. sinuosa fruit extract, namely, 2-hydroxycinnamic acid, chlorogenic acid, caffeic acid,

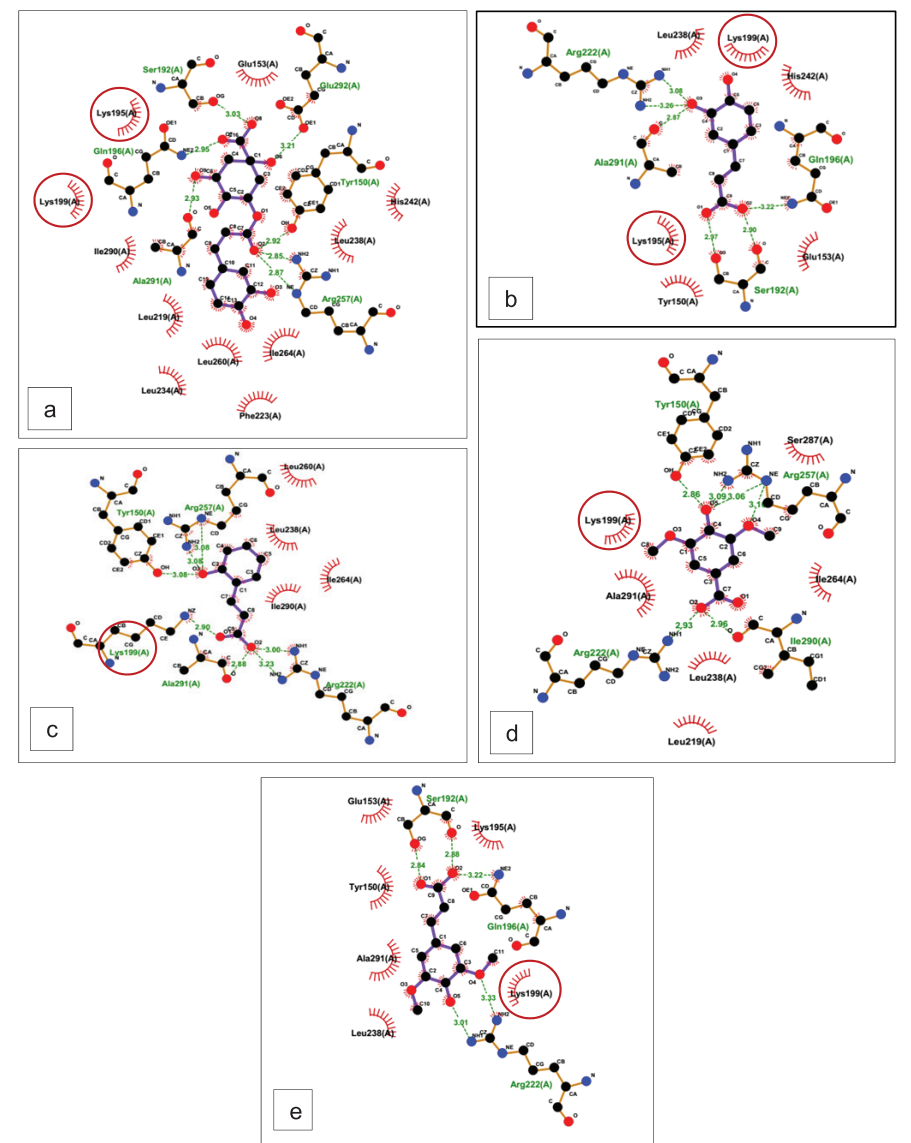

Figure 4. Antiglycation interaction (red circle) on (a) chlorogenic acid (b) caffeic acid (c) 2-hydroxycinnamic acid (d) syringic acid and (e) sinapinic acid.

sinapinic acid, ferulic acid, syringic acid, and isovanillic acid with HSA. Molecular docking is an in silico based method that is often used to understand the binding parameters of ligands (compounds) to biological macromolecules such as proteins. Previous studies 


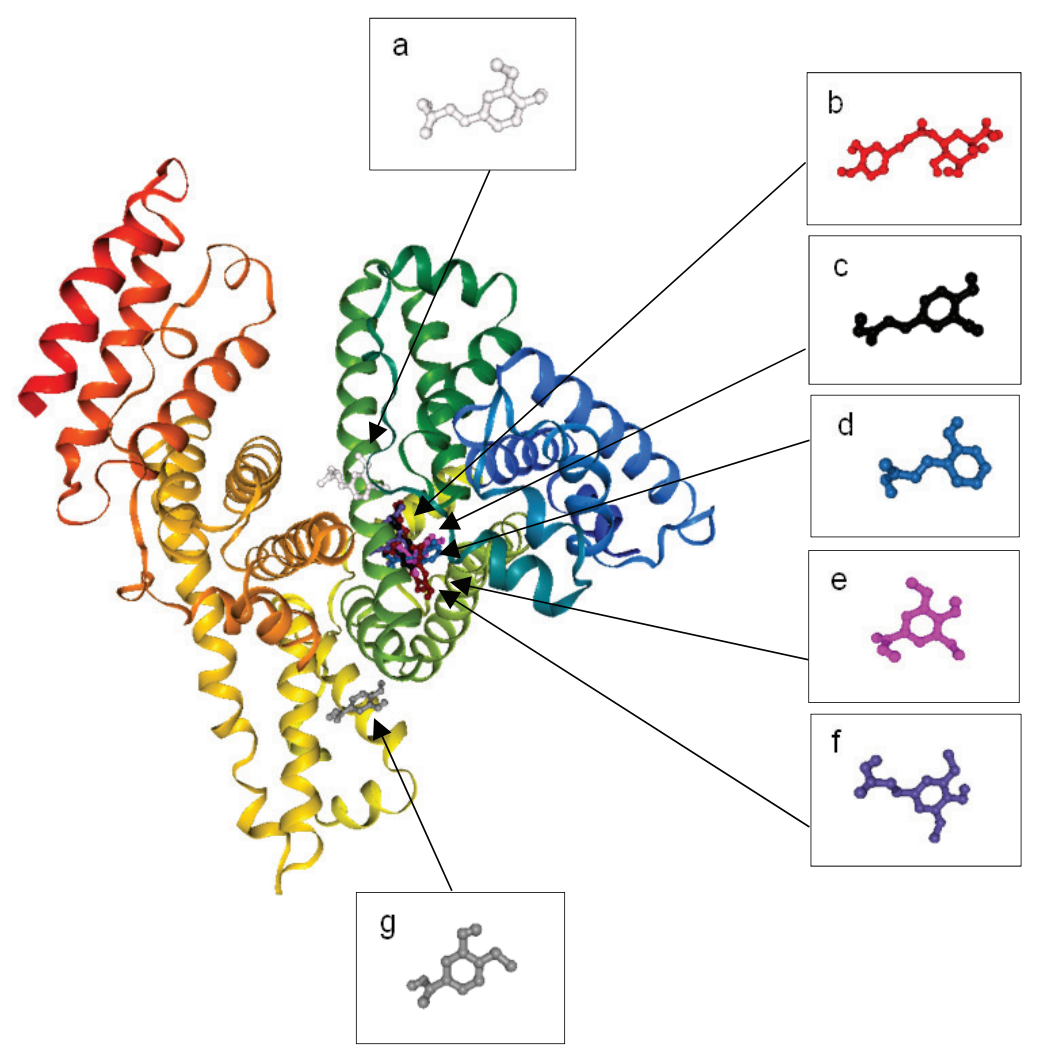

Figure 5. Position of ligands (phenolic acids of water extract S. sinuosa fruits) on HSA (a) ferulic acid (b) chlorogenic acid (c) caffeic acid (d) 2-hydrocinnamic acid (e) syringic acid (f) sinapinic acid and $(\mathrm{g})$ isovanillic acid.

confirmed that the main amino acid residues involved in the glycation process were Lys and Arg (Anguizola et al., 2013).

The docking results showed that the amino acid residues of Lys and Arg HSA interacted with the phenolic acids of $S$. sinuosa fruits through hydrophobic interactions and hydrogen bonds (Table 2). Lys190 amino acid residues interact with ferulic acid through hydrophobic interactions. Lys 195 amino acid residue interacts with sinapinic acid, chlorogenic acid, and caffeic acid through hydrophobic interactions. Lys199 amino acid residues interact with syringic acid, sinapinic acid, chlorogenic acid, and caffeic acid through hydrophobic interactions, whereas they interact with 2-hydroxycinnamic acid through hydrogen bonds. Lys351 amino acid residues interact with isovanillic acid through hydrophobic interactions. Arg222 amino acid residues interact with sinapinic acid, 2-hydroxycinnamic acid, and caffeic acid via hydrogen bonds, while the amino acid residue Arg257 interacts with syringic acid, 2-hydroxycinnamic acid, and chlorogenic acid through hydrogen bonds (Table 2). The interaction of phenolic acids and HSA through the hydrogen bonds of the amino acids lysine and arginine is in line with the statements of YildirimElikoglu and Erdem (2017), Brudzynski and Maldonado-Alvarez (2015), which showed that hydrogen bonds are formed between electronegative nitrogen or oxygen atoms, especially amino groups (-NH2) and hydroxyl groups (-OH) protein, and positively charged hydrogen atoms from the polyphenol hydroxyl groups. Hydrophobic interactions between lysine and nonpolar aromatic groups of phenolic acids are possible even though lysine is not classified as a nonpolar amino acid through its side chains. Dyson et al. (2006) stated that although lysine has not been traditionally classified as a nonpolar amino acid, it is found in many parts in proteins, so that as long as hydrogen bonds or salt bridge formations neutralize the $-\mathrm{NH} 3$ group, lysine side chains can be considered nonpolar.

It is known that Lys195 and Lys199, besides Lys525 as the main site of HSA glycation, as well as some arginine residues, such as Arg98, 160, 197, 472, and 521, are also glycation sites at HSA (Barnaby et al., 2011; Lapolla et al., 2004). Lys199 is also known to be responsible for $5 \%$ of the entire glycation process (Rondeau and Bourdon, 2011). The five phenolic acids in the fruit extract of $S$. sinuosa interact with the amino acid residues of Lys195 and/or Lys199, namely, chlorogenic acid, caffeic acid, 2-hydroxycinnamic acid, syringic acid, and sinapinic acid (Figure 5a-e). Lys 199 and Lys 195 are located at the entrance of Sudlow's site I and play a role in the reaction of glucose ring opening at the beginning of glycation at HSA (Wang et al., 2013).

Asy'ari' et al. (2019), based on the in silico analysis, stated that IB and IIA subdomains on the surface of HSA are favorite subdomains for interaction with glucose. Therefore, ligands that can interact strongly with these two subdomains can be used as good antiglycation candidates. Chlorogenic acid, caffeic acid, 2-hydroxycinnamic acid, syringic acid, and sinapinic acid are docked at the FA7 cleft located in the subdomain IIA (greenish yellow color in Figure 4a-e). Meanwhile, ferulic acid and isovanillic acid are in the subdomain IB and between subdomains IIA and IIB, respectively. Therefore, the interaction of ferulic acid, sinapinic acid, chlorogenic acid, 2-hydroxycinnamic 
acid, sinapinic acid, and caffeic acid with HSA is predicted to be able to inhibit the interaction of sugars to HSA.

\section{CONCLUSION}

The water extract of $S$. sinuosa fruits has seven identified phenolic acids: syringic acid, isovanillic acid, 2-hydroxycinnamic acid, sinapinic acid, chlorogenic acid, caffeic acid, and ferulic acid. Chlorogenic acid shows a higher binding affinity than another phenolic acid of $S$. sinuosa fruit extract. Five phenolic acids in $S$. sinuosa fruit extracts bind to HSA in the FA7 site (subdomain IIA), namely chlorogenic acid, caffeic acid, 2-hydroxycinnamic acid, syringic acid, and sinapinic acid. Meanwhile, two other phenolic acids, namely ferulic acid and isovanillic acid, respectively, bind to the FA1 site (subdomain IB) and FA6 site (between subdomains IIA and IIB). The docking results showed that chlorogenic acid, caffeic acid, syringic acid, 2-hydroxycinnamic acid, and sinapinic acid predictable potentially play a role in the process of antiglycation on the protein surface of HSA because they bonded to the amino acid residues of Lys195 and/or Lys199 as part of amino acid residues that play a role in HSA glycation. This information can provide a basis for further use of the $S$. sinuosa fruit.

\section{ACKNOWLEDGMENTS}

The authors were grateful to Laboratorium Sentral Ilmu Hayati, Brawijaya University, especially Midia Lestari Wahyu Handayani, STP, M.Sc., MP, Ph.D., for laboratory analysis and Maria Matoetina Suprijono, SP, M.Si., for in silico technical assistance.

\section{AUTHOR CONTRIBUTIONS}

All authors made substantial contributions to conception and design, acquisition of data, or analysis and interpretation of data; took part in drafting the article or revising it critically for important intellectual content; agreed to submit to the current journal; gave final approval of the version to be published; and agree to be accountable for all aspects of the work. All the authors are eligible to be an author as per the international committee of medical journal editors (ICMJE) requirements/guidelines.

\section{FUNDING}

There is no funding to report.

\section{CONFLICTS OF INTEREST}

The authors report no financial or any other conflicts of interest in this work.

\section{ETHICAL APPROVALS}

This study does not involve experiments on animals or human subjects.

\section{PUBLISHER'S NOTE}

This journal remains neutral with regard to jurisdictional claims in published institutional affiliation.

\section{REFERENCES}

Abbas G, Al-Harrasi AS, Hussain H, Hussain J, Rashid R, Choudhary MI. Antiglycation therapy: discovery of promising antiglycation agents for the management of diabetic complications. Pharm Biol, 2015; 54(2):198-206.
Anguizola J, Matsuda R, Barnaby OS, Hoy KS, Wa C, Debolt E, Koke M, Hage DS. Glycation of human serum albumin. Clin Chim Acta, 2013; 425:64-76.

Arfin S, Siddiqui GA, Naeem A, Moin S. Inhibition of advanced glycation end products by isoferulic acid and its free radical scavenging capacity: an in vitro and molecular docking study. Int J Biol Macromol, 2018; 118:1479-87.

Ascenzi P, di Masi A, Fanali G. Fasano M. Heme-based catalytic properties of human serum albumin. Cell Death Discov, 2015; 1(1):15025.

Asy'ari M, Kurniawati N, Aminin ALN. In silico study: the antiglycation potency of aloin on the protein surface of human serum albumin. IOP Conf Ser Mater Sci Eng, 2019: 509:012087.

Barnaby OS, Cerny RL, Clarke W, Hage DS. Comparison of modification sites formed on human serum albumin at various stages of glycation. Clin Chim Acta, 2011; 412:277-85.

Brudzynski K, Maldonado-Alvarez L. Polyphenol-protein complexes and their consequences for the redox activity, structure and function of honey. A current view and new hypothesis - a review. Pol J Food Nutr Sci, 2015; 65(2):71-80.

Cervantes-Laurean D, Schramm DD, Jacobson EL, Halaweish I, Bruckner GG, Boissonneault GA. Inhibition of advanced glycation end product formation on collagen by rutin and its metabolites. J Nutr Biochem, 2006; 17(8):531-40.

Colak N, Torun H, Gruz J, Strnad M, Subrtova M, Inceer H, Ayaz FA. Comparison of phenolics and phenolic acid profiles in conjunction with oxygen radical absorbing capacity (ORAC) in berries of Vaccinium artostaphylos L. and V. Myrtillus L. Pol J Food Nutr Sci, 2016; 66(2):85-91.

Cosmulescu S, Trandafir I, Nour V. Phenolic acids and flavonoids profiles of extracts from edible wild fruits and their antioxidant properties Int J Food Properties, 2017; 20(12):3124-34.

Dallakyan S, Olson AJ. Small-molecule library screening by docking with PyRx. Methods Mol Biol, 2015; 1263:243-50.

Dyson HJ, Wright PE, Scheraga HA. The role of hydrophobic interactions in initiation and propagation of protein folding. Proc Natl Acad Sci, 2006; 103(35):13057-61.

Gilson MK, Zhou HX. Calculation of protein-ligand binding affinities. Annu Rev Biophys Biomol Struct, 2007; 36:21-42.

He T, Liang Q, Luo T, Wang Y, Luo G. Study on interactions of phenolic acid-like drug candidates with bovine serum albumin by capillary electrophoresis and fluorescence spectroscopy. J Solution Chem, 2010; 39(11):1653-64.

Hwang SJ, Kim YW, Park Y, Lee HJ, Kim KW. Antiinflammatory effects of chlorogenic acid in lipopolysaccharide-stimulated RAW 264.7 cells. Inflammation Res, 2014; 63(1):81-90.

Keim AP. Pandanaceae of the island of Yapen, Papua (West New Guinea), Indonesia, with reviews their nomenclature and notes on the rediscovery of Sararanga sinuosa, and several new species and records. Blumea, 2009; 54:255-66.

La Barbera G, Capriotti AL, Cavaliere C, Piovesana S, Samperi $\mathrm{R}$, Zenezini $\mathrm{CR}$, Laganà $\mathrm{A}$. Comprehensive polyphenol profiling of a strawberry extract (Fragaria $\times$ ananassa) by ultra-high-performance liquid chromatography coupled with high-resolution mass spectrometry. Anal Bioanal Chem, 2017; 409(8):2127-42.

Lapolla A, Fedele D, Reitano R, Arico NC, Seraglia R, Traldi P, Marotta E, Tonani R. Enzymatic digestion and mass spectrometry in the study of advanced glycation end products/peptides. J Am Soc Mass Spectrom, 2004: 15:496-509.

León-González AJ, Truchado P, Tomás-Barberán FA, LópezLázaro M, Barradas MCD, Martín-Cordero C. Phenolic acids, flavonols and anthocyanins in Corema album (L.) D. Don berries. J Food Compost Anal, 2013; 29:58-63.

Li X, Wang X, Chen D, Chen S. Antioxidant activity and mechanism of protocatechuic acid in vitro. Funct Food Health Dis, 2011; $7: 232-44$

Manach C, Scalbert A, Morand C, Rémésy C,Jiménez L. Polyphenols: food sources and bioavailability. Am J Clin Nutr, 2004; 79:727-47. 
Mattila P, Hellström J, Törrönen R. Phenolic acids in berries, fruits, and beverages. J Agric Food Chem, 2006; 54:7193-9.

Purwanto Y, Munawaroh E. Ethnobotany types of pandanaceae as food in Indonesia. Berkala Penelitian Hayati, 2010.

Nile SH, Park SW. Edible berries: bioactive components and their effect on human health. Nutrition, 2014; 30:134-44.

O’Boyle NM, Banck M, James CA, Morley C, Vandermeersch T, Hutchison GR. Open babel: an open chemical toolbox. Journal of Cheminformatics, 2011;3(1):33.

Purnamasari V, Lunga N, Widjanarko SB. Morphometric characteristic, nutritional value and antioxidant activity of Sararanga sinuosa Hemsley (Pandanaceae) during ripening: a native berries of Papua, Indonesia. Pak J Bot, 2019; 52(2); doi: 10.30848/PJB2020-2(1)

Purnamasari V, Zebua LI, Soeprijono MM. Potential use of "Anggur Papua" (Sararanga sinuosa Hemsley) based on the characteristics of berries. In: Purnomo S, Hanani N, Mahfud C, Tafakresnanto C (ed.). Proceedings of national meeting: innovation of management, utilization and festival of local genetic resources. Balai Pengkajian Teknologi Pertanian, Jawa Timur, Indonesia, pp 342-9, 2018.

Rabbani G, Saeyoung NA. Structure, enzymatic activities, glycation and therapeutic potential of human serum albumin: a natural cargo. Int J Biol Macromol, 2019; 123:979-90.

Robbins RJ. Phenolic acids in foods: an overview of analytical methodology. J Agric Food Chem, 2003; 51(10):2866-687.

Rondeau P, Bourdon E. The glycation of albumin: structural and functional impacts. Biochimie, 2011; 93:645-58.

Roohk HV, Zaidi AR. A review of glycated albumin as an intermediate glycation index for controlling diabetes. J Diabetes Sci Technol, 2008; 2(6):1114-21.

Shafreen RB, Dymerski T, Namiesnik J, Jastrzębski Z, Vearasilp $\mathrm{S}$, Gorinstein S. Interaction of human serum albumin with volatiles and polyphenols from some berries. Food Hydrocoll, 2017; 72:297-303.

Shimizu I, Kohzuma T, Koga M. A proposed glycemic control marker for the future: glycated albumin. J Lab Precis Med, 2019; 4:23-3.

Stojković DS, Zivković J, Soković M, Glamočlija J, Ferreira ICFR, Janković T, Maksimović Z. Antibacterial activity of Veronica montana L. extract and of protocatechuic acid incorporated in a food system. Food Chem Toxicol, 2013; 55:209-13.

Stone, BC, Huynh KL, Poppendieck HH. Pandanaceae. In: Ubitzki $\mathrm{K}$ (ed.). The families and genera of flowering plants 3. Berlin, Germany: Springer, pp 397-40, 1998

Su X, Zhang J, Wang H, Xu J, He J, Liu L, Zhang T, Chen R, Kang J. Phenolic acid profiling, antioxidant, and anti-inflammatory activities, and miRNA regulation in the polyphenols of 16 blueberry samples from China. Molecules, 2017; 2:312.
Sun J, Xiao Z, Lin L, Lester GE, Wang Q, Harnly JM, Chena P, Profiling polyphenols in five Brassica species microgreens by UHPLCPDA-ESI/HRMSn. J Agric Food Chem, 2013; 61(46):10960-70.

Tao A, Huang Y, Shinohara Y, Caylor ML, Pashikanti S, Xu D. ezCADD: a rapid 2D/3D visualization-enabled web modeling environment for democratizing computer-aided drug design. J Chem Inf Model, 2018; 59(1):18-24.

Trott O, Olson AJ. AutoDock Vina: improving the speed and accuracy of docking with a new scoring function, efficient optimization, and multithreading. J Comput Chem, 2009; 31(2):455-61.

Ulrich P, Cerami A. Protein glycation, diabetes, and aging. Recent Prog Horm Res, 2001; 56:1-21.

Wallace AC, Laskowski RA, Thornton JM. LIGPLOT: a program to generate schematic diagrams of protein-ligand interactions. Protein Eng, $1995 ; 8: 127-34$.

Wang Y, Yu H, Shi X, Luo Z, Lin D, Huang M. Structural mechanism of ring-opening reaction of glucose by human serum albumin. $\mathrm{J}$ Biol Chem, 2013; 288:15980-7.

Wang Y, Zhang T, Xu J, Du W. Comparison of the binding affinity of chlorogenic acid with two serum albumins. International Journal of Biological Macromolecules, 2011; 48(1): 81-86.

Yildirim-Elikoglu S, Erdem YK. Interactions between milk proteins and polyphenols: binding mechanisms, related changes, and the future trends in the dairy industry. Food Rev Int, 2017; 34(7):665-97.

Zengin G, Rodrigues MJ, Abdallah HH, Custodio L, StefanucciA, Aumeeruddy MZ, Mollica A, Rengasamy KRR, Mahomoodally MF. Combination of phenolic profiles, pharmacological properties and in silico studies to provide new insights on Silene salsuginea from Turkey. Comput Biol Chem, 2008; 77:178-86.

How to cite this article:

Purnamasari V, Estiasih T, Sujuti H, Widjanarko SB. Identification of phenolic acids of Pandan anggur (Sararanga sinuosa Hemsley) fruits and their potential antiglycation through molecular docking study. J Appl Pharm Sci, 2021; 11(02):126-134. 